

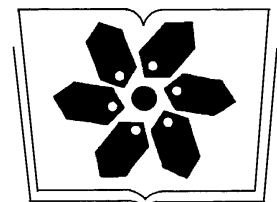

中国科学院科学出版基金资助出版

\section{生 态 学 报}

(SHENGTAI XUEBAO)

\section{第 32 卷第 8 期 2012 年 4 月 (半月刊)}

东北地区 5 种阔叶树苗木对火烧的生理响应……………………………..... 王荣, 胡海清 (2303) 梭梭木虫发生规律及其影响因子…………………………………李粉莲, 吴雪海, 王佩玲, 等 (2311) 基于遥感降尺度估算中国森林生物量的空间分布……………………刘双娜, 周 涛,舒 阳,等 (2320) 流域景观格局与河流水质的多变量相关分析……………………....赵 鹏, 夏北成,秦建桥, 等 $(2331)$ 内蒙古达春湖地区赤狐生境选择及生境景观特征分析…………………张洪海,李成涛,赎华山,等 $(2342)$ 雅鲁藏布江流域底栖动物多样性及生态评价………………………徐梦珍, 王兆印, 潘保柱, 等 $(2351)$ 用组合模型综合比较的方法分析气候变化对朱賙潜在生境的影响…………………翟天庆,李欣海 (2361) 2010 年牧区 2 代草地螟成虫迁飞的虫源分析 ……………………张 丽,张云慧, 曾 娟, 等 (2371) 基于细胞色素 $b$ 基因的中国岩羊不同地理种群遗传差异分析…………李楠楠,刘振生,王正睘,等 (2381) 喀斯特峰丛洼地不同退耕还林还草模式的土壤微生物特性……………鹿士杨,彭晚霞, 宋同清, 等 (2390) 永定河沿河沙地杨树人工林生态系统呼吸特征………………........ 方显瑞, 张志强,查同刚,等 (2400) 基于湿地植物光谱的水体总氮估测………………………………刘克, 赵文吉, 郭逍宇, 等 (2410) 背瘤丽蚌 $\mathrm{F}$ 型线粒体基因组全序列分析 ……………………………陈玲, 汪桂玲, 李家乐 (2420) 流域“源-汇”景观格局变化及其对磷污染负荷的影响——以天津于桥水库流域为例

㩐 $(2430)$ 线虫群落对抚顺煤矸石山周边土壤可溶性盐污染的响应………………张伟东, 吕 莹, 肖 荣, 等 (2439) 地上竞争对林下红松生物量分配的影响…………………………汪金松,范秀华, 范 娟, 等 (2447) 湿地松和马尾松人工林土壤甲烷代谢微生物群落的结构特征…………王 芸, 郑华, 陈法霖, 等 (2458) 马尾松和杉木树千韧皮部水溶性糖 $\delta^{13} \mathrm{C}$ 值对气象因子的响应 ………卢钰茜, 王振兴, 郑怀舟, 等 (2466) 沙坡头人工植被演替过程的土壤呼吸特征……………………………高艳红, 刘立超, 贾荣亮, 等 (2474) 豫西刺槐能源林的热值动态………………………………....... 谭晓红, 刘诗琦, 马履一, 等 (2483) 铁皮石斛种子的室内共生萌发 ………………………………………吴慧凤, 宋希强, 刘红霞 (2491) 红光与远红光比值对温室切花菊形态指标、叶面积及干物质分配的影响 扑草净对远志幼苗根系活力及氧化胁迫的影响…………………....温银元, 郭平毅, 尹美强, 等 (2506) 地表臭氧浓度增加和 UV-B 辐射增强及其复合处理对大豆光合特性的影响 细菌多样性动态………………………………葛菁萍,柴洋洋, 陈 丽, 等 (2532) 定位施肥对紫色菜园土磷素状况的影响………………………..... 孙倩倩, 王正银, 赵 欢, 等 (2539) 基于生态需水保障的农业生态补偿标准……………………………………庞爱萍, 孙涛 (2550) 保障粮食安全造成的生态价值损失评估模型及应用…………………芦蔚叶, 姜志德, 张应龙, 等 $(2561)$ 专论与综述

疏浚泥用于滨海湿地生态工程现状及在我国应用潜力………………黄华梅, 高 杨, 王银霞, 等 $(2571)$ 问题讨论

厌氧氨氧化菌群体感应系统研究……………………………丁 叒, 郑平, 张 萌, 等 $(2581)$ 基于形态结构特征的洞庭湖湖泊健康评价……………………帅红, 李景保, 夏北成, 等 (2588) 研究简报 黄土高原不同树种枯落叶混合分解效应…………………………刘增文,杜良贞,张晓䂀, 等 (2596) 不同经营类型毛竹林土壤活性有机碳的差异……………………… 马少杰,李正才, 王 斌, 等 (2603) 千旱对辣椒光合作用及相关生理特性的影响………………………欧立军,陈 波,邹学校 (2612) 硅和千旱胁迫对水稻叶片光合特性和矿质养分吸收的影响 ……………陈 伟, 蔡昆争, 陈基宁 (2620) 期刊基本参数: CN 11-2031/Q * 1981* m * $16 * 326 * \mathrm{zh} * \mathrm{P} * ¥ 70.00 * 1510 * 36 * 2012-04$

封面图说: 红树林粗大的气生根——红树林是热带、亚热带海湾及河口泥滩上特有的常绿灌木或乔木群落。由于海水环境条 件特殊,红树林植物具有一系列特殊的生态和生理特征。其中之一就是气根,红树从根部长出许多指状的气生根露 出海滩地面, 以便在退潮时甚至潮水淹没时用以通气, 故称呼吸根。在中国,红树林主要分布在海南、广西、广东和 福建省沿海, 它一般分布于高潮线与低潮线之间的潮间带,往往潮差越大、红树的呼吸根就长得越高越粗大。

彩图提供: 陈建伟教授 北京林业大学 E-mail: cites. chenjw@163.com 


\title{
DOI: $10.5846 /$ stxb201103070270
}

王荣, 胡海清. 东北地区 5 种阔叶树苗木对火烧的生理响应. 生态学报,2012,32(8):2303-2310.

Wang R,Hu H Q. Physiological responses of five deciduous broad-leaved tree seedlings in the Northeast Area of China to burning. Acta Ecologica Sinica, $2012,32(8): 2303-2310$.

\section{东北地区 5 种阔叶树苗木对火烧的生理响应}

\author{
王 荣, 胡海清* \\ (东北林业大学,哈尔滨 150040 )
}

\begin{abstract}
摘要: 以 3 年生水曲柳、胡桃楸、蒙古栎、黄菠萝、白桦为研究对象, 研究 3 种火烧处理 (T1 处理: 对叶片火烧; T2 处理: 对枝火 烧; T3 处理:对茎火烧) 对幼树丙二醛(MDA) 含量、叶绿素含量和净光合速率的影响。结果显示: 5 种幼树火害叶( T1 处理) 丙 二醛含量与对照相比都显著提高, 说明幼树叶片细胞都受到了火的影响, 发生了膜脂过氧化作用。水曲柳、胡桃楸、白桦火害叶 ( $\mathrm{T} 1$ 处理) 叶绿素含量与对照相比显著提高; 水曲柳、胡桃楸火害叶 ( $\mathrm{T} 1$ 处理) 叶绿素 $\mathrm{a} / \mathrm{b}$ 与对照相比显著降低。火烧处理后幼 树新生叶丙二醛含量的变化因物种而异。5 种幼树 3 种火烧处理后新生叶叶绿素含量除蒙古栋的茎处理和胡桃楸的枝处理显 著降低外,大多表现为升高的趋势; 新生叶叶绿素 $\mathrm{a} / \mathrm{b}$ 的变化因物种而异。 5 种幼树 3 种火烧处理后新生叶净光合速率除蒙古 栋的茎处理显著降低外,其他都有不同程度的提高。表明火烧提高了幼树的光合作用能力。
\end{abstract}

关键词: 幼树; 火烧处理;丙二醛含量; 叶绿素含量

\section{Physiological responses of five deciduous broad-leaved tree seedlings in the Northeast Area of China to burning}

WANG Rong, HU Haiqing*

Northeast Forestry University, Harbin 150040 , China

Abstract: In the present study, the effects of burning treatments on seedlings of five tree species were investigated. Using pot-grown 3-year-old seedlings of Fraxinus mandshurica, Juglans mandshurica, Quercus mongolica, Phellodendron amrense, and Betula platyphyla as the test materials, three burning treatment methods were applied, including T1 (leaf burn), T2 (branch burn), and T3 (stem burn). The malondialdehyde (MDA) and chlorophyll contents in seedling leaves were detected, and the net photosynthetic rate was determined.

The heat energy from the fire treatments is transferred to plant tissues by conduction and radiation. Burning can damage cell membranes, resulting in lipid peroxidation and production of MDA. The product of lipid peroxidation, MDA, was used to estimate the degree of damage to the cell membranes. Lipid peroxidation can occur during organ senescence or as a result of stress damage. In T1 treatment, the MDA contents in leaves from five species were significantly higher than their respective controls, indicating that leaf cells were destroyed by fire and that membrane lipids in leaf cells had undergone peroxidation. Moreover, in T1 treatment, the chlorophyll contents were higher in the leaves of $F$. mandshurica, $J$. mandshurica, and B. platyphyla than in their respective controls, but similar in the leaves of $Q$. mongolica and $P$. amrense and their respective controls. In addition, in $\mathrm{T} 1$ treatment, the chlorophyll $\mathrm{a} / \mathrm{b}$ ratio in the leaves from $F$. mandshurica and J. mandshurica was lower than that in controls, respectively. However, in Q. mongolica, P. amrense, and B. platyphyla, the chlorophyll a/b ratio was similar with controls. Also, there were higher MDA contents in leaves

基金项目: 国家重点基础研究发展规划(973 计划)项目(2011CB403200); 公益性行业科研专项经费项目(201004003)

收稿日期:2011-03-07; 修订日期:2011-09-19

* 通讯作者 Corresponding author. E-mail: huhq@ nefu. edu. cn 
after the T2 and T3 treatments of $Q$. mongolica, the T3 treatment of $J$. mandshurica, and the T2 and T3 treatments of $B$. platyphyla. In terms of cell membrane stability, the membranes of species that were not well adapted to fire were weakened by fire damage. However, in seedlings that are well-adapted to fire, the MDA contents in young fire-treated leaves were lower than those in the control. These included the T1 and T2 treatments of $F$. mandshurica and the T2 and T3 treatments of $P$. amrense. The lower MDA contents in the burned tissues indicated that cell membrane stability is enhanced by fire treatments in young leaves and saplings from the well fire-adapted species.

Chlorophyll reflects the photosynthesis, the chlorophyll content, and the chlorophyll $\mathrm{a} / \mathrm{b}$ ratio are important indicators of the physiological condition of the leaves. In all five species, the chlorophyll contents in the leaves increased after the T1, T2, and T3 treatments, except in T3 treatment of $Q$. mongolica and T2 treatment of $J$. mandshurica. The change in the chlorophyll $\mathrm{a} / \mathrm{b}$ after fire treatments varied among the five species. The net photosynthetic rate, which is the most important index for photosynthesis, increased to varying extents in the five species in the T1, T2, and T3 treatments. The only exception was the T3 treatment of $Q$. mongolica. Fire influenced the photosynthesis of saplings by affecting physiological metabolism. The results of these experiments indicated that fire affected the growth of these tree species.

Key Words: sapling; burning; MDA contents; content of chlorophyll

火是森林生态系统中一个活跃因子, 火对生态系统作用有利或是有害, 主要取决于火作用的时间和强 度。一般来讲, 低强度火和一定周期的林火有利于维持生态系统的稳定, 有益于森林的天然更新和林地生 产力的提高。因此, 只有在理论和实践上对火有明确的认识, 了解和掌握火的作用规律, 才能充分利用火有益 的一面,使火成为人类进行生产生活活动的有益工具和手段。用火实践在我国开展的比较广泛,如农业的烧 荒和 “炼山” 整地、牧场的清理、林业上的营林用火等以及计划火烧等 ${ }^{[1-2]}$ 。蒙古柇、白桦、水曲柳、黄菠萝和胡 桃楸是东北地区重要树种, 具有极高的经济价值和生态价值。森林火灾对这 5 种阔叶树种的生长和种群演替 产生了重要的影响。蒙古柇是萌生能力很强的阳性树种, 适应频繁的火干扰, 有一定的抗火能力。白桦适应 性强, 耐痊薄、耐严寒, 天然更新良好, 也是采伐迹地和火烧迹地天然更新的先锋树种。水曲柳、黄菠萝、胡桃 楸是东北三大硬阔树种, 是阔叶红松林的主要伴生树种, 并与极树、榆树和色木等硬阔叶树一起形成各种林型 的硬阔叶林,在次生林的演替中起着非常重要的作用。

有关火对植物生理生化影响的研究不多。耿玉超 ${ }^{[3]}$ 等研究了火后樟子松、红松的叶绿素含量和细胞膜 透性, 发现火烧后叶子的叶绿素含量增加, 特别是当年新萌发的叶子其叶绿素含量增加更显著, 受害愈严重, 叶绿素增加的量愈多; 上年生叶与对照木细胞透性比较, 干害木略大于对照。周道玮 ${ }^{[4]}$ 等研究了草原火烧对 植物叶绿素含量的影响, 得出火烧对植物体内叶绿素含量的影响没有明显的规律, 但叶绿素 $\mathrm{a}$ 和叶绿素 $\mathrm{b}$ 的 变化趋势一致。Eric L. K 等研究发现火烧后糖枫的光合作用比未火烧的提高 $42 \%$, 同时气孔导度也增加, 叶 片 $\mathrm{N}$ 含量增加 ${ }^{[5]}$ 。

火烧产生的热量, 通过传导、辐射进人植物活组织, 首先产生对叶片细胞膜的损伤, 使细胞膜脂过氧化, 产 生丙二醛。丙二醛含量过高或过低均可能影响植物正常的光合作用 ${ }^{[6]}$ 。植物利用叶片进行光合作用产生有 机物质。净光合速率是研究植物光合作用状况的最重要指标。叶绿素是叶片进行光合生理作用的基础, 叶绿 素含量和叶绿素 $\mathrm{a} / \mathrm{b}$ 值是反映光合器官生理状况的重要指标 ${ }^{[7]}$ 。火烧对树木生理代谢产生影响, 从而影响 到叶片的光合作用, 影响到树木本身的生长。本文通过火烧取样测定幼树叶片丙二醛含量、叶绿素含量和净 光合速率, 来探讨火烧对幼树叶片细胞膜和光合作用的影响, 为更好的研究火烧对树木生长的影响提供植物 生理方面的依据,进而更科学的指导营林用火和计划火烧。

\section{1 材料与方法}

\section{1 试验材料及培养}

试验树种是 3 年生水曲柳 (Faxinus mandshurica)、胡桃楸 (Juglans mandshurica) 和蒙古栋 ( Quercus 
mongolica) 、黄菠夢( Phelodondrom amurense)、白桦(Betula platyphylla)。选自黑龙江省五常市林业苗圃。5 月 初将幼树裸根移栽到东北林业大学哈尔滨市城市林业示范基地实验大棚外, 栽植在直径为 $38 \mathrm{~cm}$, 高为 $45 \mathrm{~cm}$ 的塑料桶内,各栽植 50 株,每桶内栽植 1 株幼树,共计 250 株。3 d 浇 1 次水,未施肥。

\section{2 火烧处理}

7 月 18 日用汽油喷灯对幼树进行 3 种火烧处理(火焰大小一致, 火焰最前端接触叶、茎)。T1 处理(叶片 火烧): 对幼树树叶从上到下均匀喷烧 $30 \mathrm{~s}$, 叶片出现不同程度萎䔍、卷曲, 颜色变黑; T2 处理 (枝火烧) : 对幼 树的枝条均匀喷烧 $60 \mathrm{~s}$; T3 处理 (茎火烧) : 对幼树茎上下均匀喷烧 $90 \mathrm{~s}$ 。对照 (对照) : 未进行火烧处理。各 火烧处理幼树 10 株。

\section{3 测定方法和火烧处理后状况}

火烧 7-10 d 后, T1 处理幼树的部分叶片未受到明显影响,部分叶片边缘或 1/2 叶片被烧死; T2 处理幼 树小枝被烧死,从茎上长出新枝新叶; T3 处理幼树茎被烧死,在下部接近根部长出叶片。

叶片选向阳同一枝位的,各处理 3 次测量重复。由于火害叶余留面积较小, 无法准确测量净光合速率, 所 以只对新生叶净光合速率进行测量。

丙二醛含量测定采用硫代巴比妥酸法测定 ${ }^{[8]}$ 。

叶绿素含量测定采用混合丙酮与无水乙醇的体积比为 $1: 1$ 浸提法 ${ }^{[9]}$ 。

净光合速率测定采用 $\mathrm{Li}-\mathrm{COR} 6400$ 进行测定。人射光强设为 $1000 \mu \mathrm{mol} \cdot \mathrm{m}^{-2} \cdot \mathrm{s}^{-1}$ 。9:00-11:30(天气晴, 无风)。

\section{4 数据处理}

采用 Microsoft Excel 和 SPSS17.0 进行数据处理。

\section{2 结果}

2.1 火烧对幼树丙二醛含量的影响

2.1 .1 火害叶丙二醛含量的变化

经测定, 火烧后 5 种幼树叶片丙二醛含量呈现不同程度的提高, 与对照差异都达到显著水平 (图 1 )。其 中, 火烧后蒙古柇叶片丙二醛含量提高最多, 比对照提高了 $72.45 \%$, 达到了 $31.32 \mu \mathrm{mol} / \mathrm{L}$, 胡桃楸叶片丙二 醛含量提高最少, 比对照提高 $11.08 \%$, 水曲柳、黄菠萝、白桦叶片丙二醛含量分别比对照提高了 $22.74 \%$ 、 $13.50 \% 、 16.13 \%$ 。由于 M DA 含量是反映细胞膜脂过氧化作用的指标, 蒙古栋叶片丙二醛含量提高最多, 说 明火烧后蒙古栋叶片膜脂过氧化程度最高, 细胞膜受到的伤害最大; 胡桃梑叶片丙二醛含量提高最少, 说明其 膜脂过氧化程度最低, 细胞膜受到的伤害最小。

2.1 .2 火烧后幼树新生叶丙二醛含量的变化

对各幼树分别进行 3 种火烧处理后, 新生叶丙二醛含量呈现不同的变化 (图 2)。对叶火烧后, 水曲柳新 生叶丙二醛含量与对照相比显著降低, 其他 4 种幼树丙二醛含量与对照差异不显著。对枝火烧后, 蒙古栎、白 桦新生叶丙二醛含量与对照相比显著提高, 水曲柳、黄菠萝新生叶丙二醛含量与对照相比显著降低, 胡桃楸新 生叶丙二醛含量与对照差异不显著。对茎火烧后, 蒙古栋、胡桃楸、白桦新生叶丙二醛含量与对照相比显著提 高, 黄菠萝新生叶丙二醛含量与对照相比显著降低, 水曲柳新生叶丙二醛含量与对照差异不显著。说明各火 烧处理对新生叶丙二醛含量影响是不同的。

2.2 火烧对幼树叶片叶绿素含量和新生叶净光合速率的影响

2.2.1 火害叶叶绿素含量的变化

火烧后,5 种幼树叶片的叶绿素含量都发生了一定的变化 (图 3), 火害叶的叶绿素含量都比对照提高。 其中, 水曲柳、胡桃楸、白桦比对照显著提高, 分别提高了 $34.60 \% 、 31.69 \% 、 84.60 \%$, 白桦提高最大, 达到了 $1.5432 \mathrm{mg} / \mathrm{g}$ 鲜重。蒙古柇和黄菠萝与对照差异未达到显著水平。火烧后, 叶片叶绿素 $\mathrm{a} / \mathrm{b}$ 也发生了不同的 变化(图 4)。水曲柳和胡桃楸叶片叶绿素 a/b 比对照显著降低, 分别降低了 7.85\%、2.19\%, 其他 3 种幼树 
火害叶叶绿素 $\mathrm{a} / \mathrm{b}$ 与对照差异不显著。

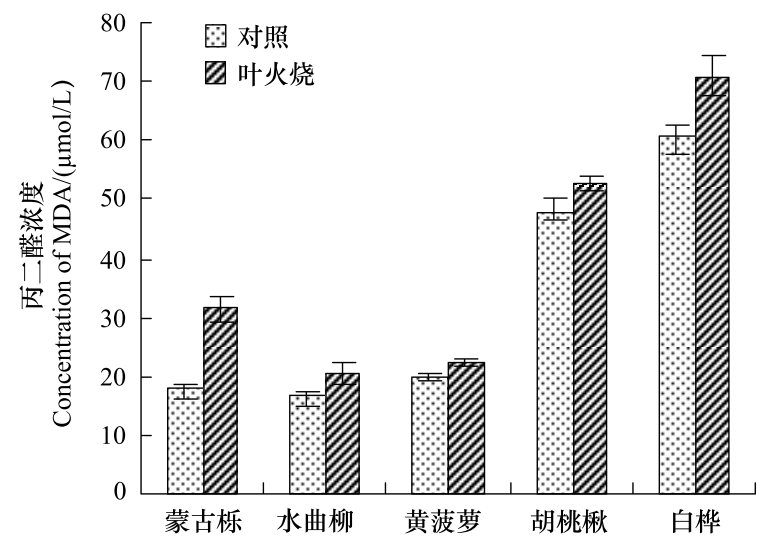

图 1 幼树火害叶丙二醛含量

Fig. 1 The MDA contents of seedlings' leaf destroyed by fire

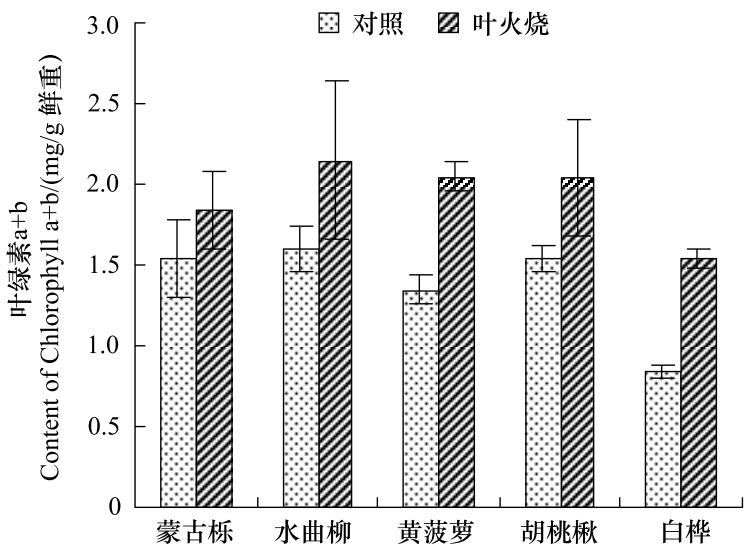

图 3 火害叶叶绿素 $\mathbf{a}+\mathbf{b}$ 含量

Fig. 3 Content of chlorophyll $a+b$ of the seedlings' leaves destroyed by fire

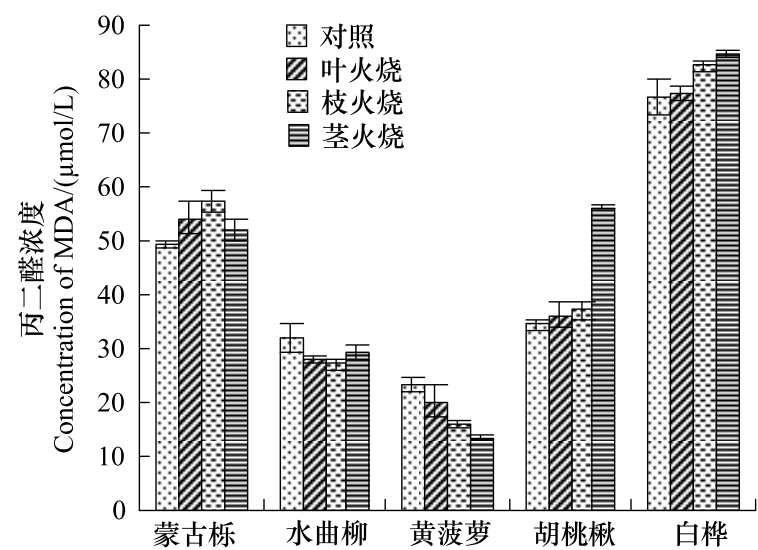

图 2 火烧后幼树新生叶丙二醛含量

Fig. 2 The MDA contents of the new leaves following burning

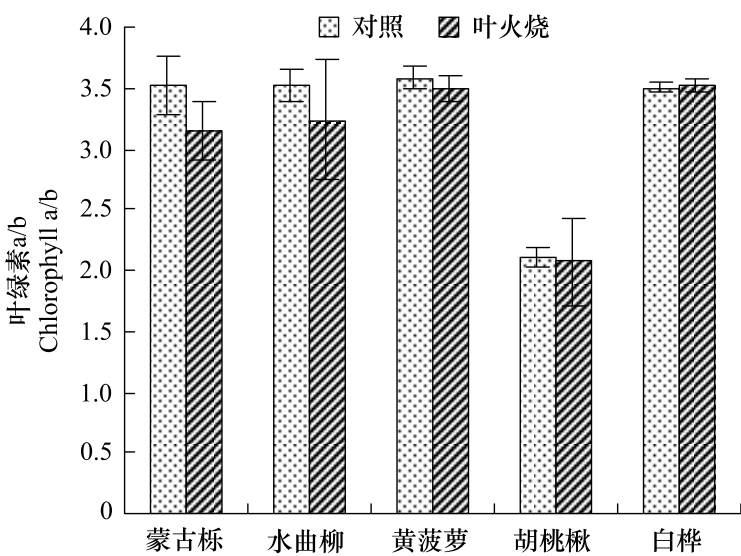

图 4 火害叶叶绿素 $\mathbf{a} / \mathbf{b}$

Fig. 4 Content of chlorophylla/b of the seedlings' leaves destroyed by fire

\subsection{2 火烧后幼树新生叶叶绿素含量的变化}

各幼树叶片火烧后, 新生叶叶绿素含量与对照相比都提高 (图 5)。其中水曲柳、黄菠萝、胡桃楸、白桦叶 绿素含量比对照显著提高, 分别提高了 $56.46 \% 、 136.20 \% 、 61.37 \% 、 35.53 \%$ 。蒙古栋叶片叶绿素含量与对 照差异不显著。对枝火烧后, 各幼树叶绿素含量与对照差异显著。其中, 蒙古栎、水曲柳、黄菠萝、白桦叶片叶 绿素含量都比对照显著提高, 分别提高了 $28.73 \% 、 19.76 \% 、 101.99 \% 、 52.49 \%$ 。胡桃楸新生叶叶绿素含量 与对照相比显著降低,降低了 $18.33 \%$ 。对茎火烧后,5 种幼树叶片叶绿素含量与对照差异显著。其中, 蒙古 栋叶绿素含量比对照显著降低 $28.75 \%$; 其他幼树叶绿素含量都比对照提高, 提高大小顺序是黄菠萝提高 $142.05 \%$ 、白华提高 $77.95 \%$ 、胡桃楸提高 $36.73 \%$ 、水曲柳提高 $31.46 \%$ 。说明火烧后,部分幼树新生叶的光 合能力提高。

各幼树叶片火烧后, 黄菠夢、胡桃楸和白桦叶片叶绿素 $\mathrm{a} / \mathrm{b}$ 比对照显著提高, 分别提高 $12.90 \%$ 、 $17.10 \% 、 8.04 \%$ (图 6)。而蒙古栋和水曲柳与对照差异不显著, 但比对照略有降低。对枝火烧后, 黄菠萝和 胡桃楸新生叶叶绿素 $\mathrm{a} / \mathrm{b}$ 比对照显著提高, 分别提高 $10.20 \% 、 47.32 \%$, 蒙古栋新生叶叶绿素 $\mathrm{a} / \mathrm{b}$ 比对照显著 降低,降低了 $8.01 \%$, 水曲柳和白桦新生叶叶绿素 $\mathrm{a} / \mathrm{b}$ 与对照差异不显著,但水曲柳比对照提高, 白桦比对照 
降低。对茎火烧后,蒙古柇和白桦叶绿素 $\mathrm{a} / \mathrm{b}$ 显著降低, 分别降低了 7.50\%、4. 64\% ; 而胡桃楸、黄菠萝新生 叶叶绿素 $\mathrm{a} / \mathrm{b}$ 显著提高,分别提高了 $22.86 \% 、 1.16 \%$ 。

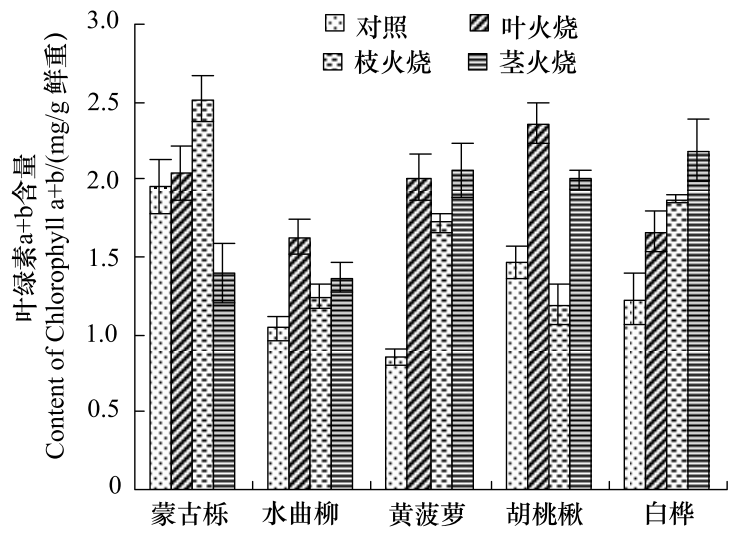

图 5 火烧后幼树新生叶的叶绿素 $\mathbf{a}+\mathbf{b}$

Fig. 5 Content of chlorophylla $+b$ of the seedlings' new leaves following burning

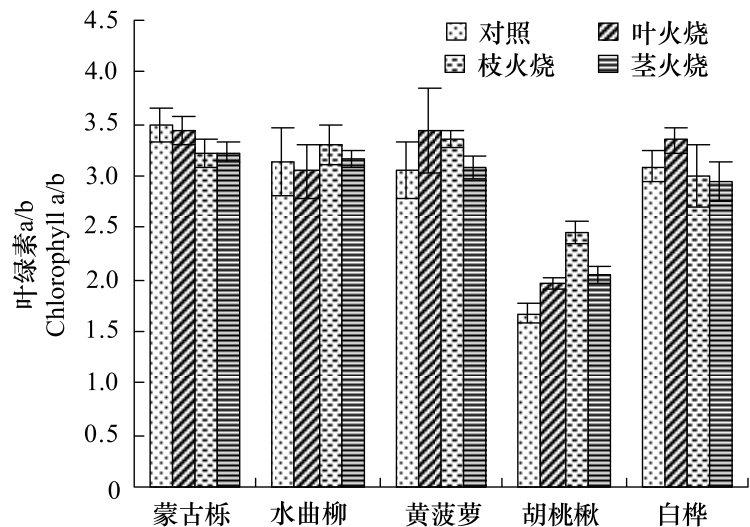

图 6 火烧后幼树新生叶叶绿素 a/b

Fig. 6 Content of chlorophyll $a / b$ of the seedlings' new leaves following burning

\subsection{3 火烧后幼树新生叶净光合速率的变化}

净光合速率是一定时间内,植物同化的总光合产物与呼吸消耗的光合产物之差。净光合速率是研究植物 光合作用状况的最重要指标。

对叶火烧后, 5 种幼树新生叶的净光合速率均提高。其中,胡桃楸、蒙古栎、白桦新生叶净光合速率与对 照差异显著, 比对照分别提高 $47.81 \% 、 37.61 \%$ 、 $54.60 \%$ 。水曲柳和黄菠萝新生叶净光合速率与对照差异不 显著。对枝火烧后, 5 种幼树新生叶的净光合速率都提高。其中,水曲柳、胡桃楸和白桦新生叶净光合速率与 对照差异达显著水平, 分别比对照提高了 $57.96 \% 、 29.89 \% 、 87.69 \%$ 。蒙古栋和黄菠萝新生叶净光合速率与 对照差异不显著。对茎火烧后, 蒙古栎新生叶净光合速率比对照显著降低,降低了 $29.81 \%$ 。水曲柳和白桦 新生叶净光合速率比对照显著提高, 分别提高了 $47.51 \% 、 54.16 \%$ 。黄菠萝新生叶净光合速率与对照差异 不显著(表 1)。

\section{表 1 火烧后幼树新生叶净光合速率}

Table 1 The net photosynthetic rate of the seedling's new leaves following burning

\begin{tabular}{llllll}
\hline $\begin{array}{l}\text { 处理 } \\
\text { Treatment }\end{array}$ & $\begin{array}{c}\text { 蒙古柇 } \\
\text { Quercus } \\
\text { mongolica }\end{array}$ & $\begin{array}{c}\text { 水曲柳 } \\
\text { Faxinus } \\
\text { mandshurica }\end{array}$ & $\begin{array}{c}\text { 黄菠萝 } \\
\text { Phelodondrom } \\
\text { amurense }\end{array}$ & $\begin{array}{c}\text { 胡桃枎 } \\
\text { Juglans } \\
\text { mandshurica }\end{array}$ & $\begin{array}{c}\text { 白桦 } \\
\text { Betula } \\
\text { platyphylla }\end{array}$ \\
\hline 对照 & $10.90 \pm 0.70$ & $7.66 \pm 0.49$ & $12.93 \pm 0.26$ & $8.93 \pm 0.49$ & $8.81 \pm 0.47$ \\
$\mathrm{~T} 1$ & $15.00 \pm 0.94 \mathrm{a}$ & $8.59 \pm 0.51$ & $14.88 \pm 0.19$ & $13.2 \pm 0.42 \mathrm{a}$ & $13.62 \pm 0.27 \mathrm{a}$ \\
变化率/\% & 37.61 & 12.14 & 15.11 & 47.81 & 54.60 \\
$\mathrm{~T} 2$ & $12.51 \pm 0.60$ & $12.1 \pm 0.66 \mathrm{a}$ & $14.33 \pm 2.35$ & $11.6 \pm 1.19 \mathrm{a}$ & $16.54 \pm 0.87 \mathrm{a}$ \\
变化率/\% & 14.77 & 57.96 & 10.81 & 29.89 & 87.69 \\
T3 & $7.65 \pm 0.28 \mathrm{a}$ & $11.3 \pm 1.15 \mathrm{a}$ & $14.55 \pm 1.45$ & $11.4 \pm 0.53 \mathrm{a}$ & $13.58 \pm 0.30 \mathrm{a}$ \\
变化率/\% & -29.81 & 47.51 & 12.52 & 27.65 & 54.16 \\
\hline
\end{tabular}

表中数据为 3 次试验重复结果 (平均值 \pm 标准误查), 字母 $\mathrm{a}$ 表示与对照差异显著;净光合速率单位: $\mu \mathrm{mol} \cdot \mathrm{m}^{-2} \cdot \mathrm{s}^{-1}$

\section{3 讨论与结论}

丙二醛 (MDA) 具有很强的细胞毒性,对膜和细胞中的许多生物功能分子如蛋白质、核酸和酶等均具有很 强的破坏作用, 并参与破坏生物膜的结构与功能, 是膜脂过氧化的产物而被用于衡量植物细胞膜受损程 度 ${ }^{[10]}$ 。植物器官衰老或在逆境下遭受伤害, 往往发生膜脂过氧化作用 ${ }^{[11-12]}$ 。脂质过氧化主要是有活性氧、自 
由基,特别是 $\cdot \mathrm{OH} 、 \mathrm{O}_{2}^{-}$启动经连锁反应而生成。 $\mathrm{MDA}$ 积累越多, 活性氧、自由基等含量越高, 表明细胞膜脂 过氧化程度越高 ${ }^{[13]}$ 。

火烧后 5 种幼树火害叶丙二醛含量都比对照显著提高, 说明幼树叶片细胞都受到了火的破坏, 发生了膜 脂过氧化作用。其中蒙古栋丙二醛含量提高的最多, 说明火烧后蒙古栋叶片的膜脂过氧化程度是最强的, 产 生的活性氧、自由基等含量是最多的,对叶片细胞的破坏是最强的; 其次是水曲柳; 火烧对黄菠萝、胡桃楸、白 桦火害叶的破坏相差不多。火烧后各处理新生叶丙二醛含量的变化没有一定的规律。蒙古栎的枝火烧和茎 火烧、胡桃楸的茎火烧、白桦的枝火烧和茎火烧处理丙二醛含量与对照相比是显著提高的, 从细胞膜稳定性角 度来看, 说明火烧使幼树新生叶细胞膜的稳定性减弱, 幼树对火没有较好的适应性, 受到的火的伤害较大, 不 利于其生长; 而水曲柳的叶火烧和枝火烧、黄菠萝的枝火烧和茎火烧处理新生叶丙二醛含量与对照相比是显 著降低的, 说明火后幼树新生叶细胞膜的稳定性增强, 幼树对火有较好的适应性, 有利于其生长; 蒙古柇的叶 火烧处理、水曲柳的枝火烧处理、黄菠萝的叶火烧处理、胡桃楸的叶火烧处理和枝火烧处理、白桦的叶火烧处 理新生叶丙二醛含量与对照相比差异不显著, 说明火烧对其新生叶影响不显著。

植物细胞中的叶绿素是光合作用中重要的一类色素分子,光合作用的重要物质,其含量的高低在很大程 度上反映了植株的生长状况和叶片的光合能力 ${ }^{[14]}$ 。叶绿素在植物体中的含量及存在状态受植物内部因子和 光照、温度等多种环境因素的影响, 易发生改变。当植物受逆境胁迫时, 植物感知胁迫作用后, 通常表现出光 合作用下降, 光合色素含量降低 ${ }^{[15]}$, 而叶绿素 $\mathrm{a} / \mathrm{b}$ 值升高。不过对耐性较强的植物来说, 叶绿素含量降低比 较缓慢, 叶绿素 $\mathrm{a} / \mathrm{b}$ 值升高也比较平稳 ${ }^{[16]}$ 。许多研究结果表明, 在各种逆境胁迫下, 植物体内叶绿素均会受 到不同程度破坏, 使其含量降低 ${ }^{[17]}$ 。而本研究中, 水曲柳、胡桃楸和白桦火害叶叶绿素含量显著提高, 说明火 烧刺激了幼树叶绿素的合成。其中水曲柳和胡桃楸的叶绿素 $\mathrm{a} / \mathrm{b}$ 值又显著的降低, 当叶绿素 $\mathrm{a} / \mathrm{b}$ 比值降低 时, 提高植物对蓝紫光的利用, 从而提高其光能利用率 ${ }^{[18]}$, 本研究说明火烧使这两种幼树的光能利用率得到 提高, 使吸收到的光能得到更大的利用。蒙古栋和黄菠萝的叶绿素含量与对照差异不显著, 说明火烧对蒙古 栋和黄菠萝的叶绿素含量的影响不大。

火烧后各幼树新生叶叶绿素含量、叶绿素 $\mathrm{a} / \mathrm{b}$ 和净光合速率因楖种及火烧处理的不同呈现不同的变化。 其中, 对叶火烧后, 胡桃楸和白桦新生叶的净光合速率和叶绿素含量及叶绿素 $\mathrm{a} / \mathrm{b}$ 的变化表现出一致性,均显 著提高, 说明火烧后新生叶光能利用率降低,但是可能由于叶绿素含量的提高, 净光合速率也提高。水曲柳、 黄菠萝和蒙古栋新生叶的净光合速率和叶绿素含量及叶绿素 $\mathrm{a} / \mathrm{b}$ 的变化没有表现出一致性: 水曲柳和黄菠萝 新生叶的叶绿素含量都显著提高, 而净光合速率没有显著变化; 蒙古栋新生叶叶绿素含量和叶绿素 $\mathrm{a} / \mathrm{b}$ 无明 显变化,净光合速率却显著提高, 说明叶绿素不是影响其光合作用的主要因素, 火烧刺激了光合机构机能, 使 得光合作用能力增强。对枝火烧后, 水曲柳、白桦新生叶叶绿素含量都显著提高, 使得净光合速率也显著提 高。胡桃楸新生叶净光合速率显著提高, 但是叶绿素含量是显著降低的。蒙古栋和黄菠萝新生叶光能利用率 提高, 叶绿素含量也提高, 但是其净光合速率没有受到显著影响。对茎火烧后,蒙古柇的新生叶净光合速率、 叶绿素含量和叶绿素 $\mathrm{a} / \mathrm{b}$ 与对照相比都显著降低, 说明火烧提高了其新生叶的光能利用率, 却降低了叶绿素 含量, 导致净光合速率的降低; 水曲柳、白桦和胡桃楸新生叶由于叶绿素含量的提高, 净光合速率也提高; 白桦 新生叶的光能利用率提高, 而胡桃楸新生叶的光能利用率降低。

以上可知, 火烧使 5 种幼树火害叶发生了膜脂过氧化作用, 叶绿素含量不同程度的提高。各种火烧处理 后幼树新生叶丙二醛含量、叶绿素含量和净光合速率的变化因树种及火烧处理方法不同而异。因此, 只要针 对不同树种采取不同火烧方法, 能够增强其细胞的稳定性, 提高光能利用率和光合能力。

在东北地区, 火常常是森林演替的重要因素, 同时也对当地顶级群落或地带性植被的形成有重要影响。

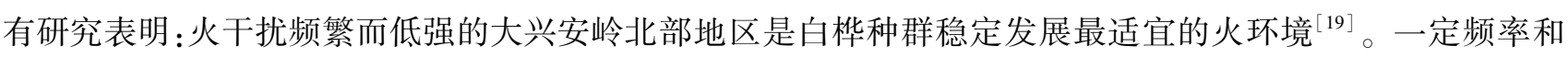
低强度的火烧有利于高山松纯林的维持和稳定 ${ }^{[20]}$ 。一定间隔期的中轻度火干扰有益于兴安落叶松群落 ${ }^{[21]}$ 。 火烧时树木受到高温刺激, 使树木处于一种致死温度以下的不良环境的锻炼, 经过一定时间后, 树木增加对这 
种不良刺激的抵抗力,从而改变其内部生理特点,所以,低强度火烧有类似于农业中 “蹲苗” 的作用, 根部受到 热刺激, 根系更发达, 形态结构和生理机能都能得到改善, 促进各种代谢更加旺盛, 因此植物的对于火烧的生 理生化响应,与植物能否适应一定的火环境有一定的联系; 也与该种植物的天然条件下群落存在有一定的 联系。

\section{References:}

[ 1 ] Zhou Y Y. Avegetation of Da Xing' an Ling in China. Beijing: Science Press, 1991.

[ 2 ] Hu H Q. Forest Fires and the Environment. Harbin: Northeast Forestry University Press, 1999.

[ 3 ] Hu H Q, Liu H R, Geng Y H. Influence of fire on korean pine and mongolian scots pine trees in plantation. Journal of Northeast Forestry University, 1992, 20(2): 43-48.

[ 4 ] Zhou D W, Jiang S C, Hu Y J. Changes in plant height growth, moisture and chlorophyll content following a grassland burning. Journal of Northeast Normal University: Natural Science Edition, 1999, (4) : 91-95.

[ 5 ] Kruger E L, Reich P B. Responses of hardwood regeneration to fire in mesic forest openings. II. Leaf gas exchange, nitrogen concentration, and water status. Canadian Journal of Forest Research, 1997, (27) : 1832- 1840.

[ 6 ] Tang C F, Liu Y G , Zeng G M, Li C F, Xu W H. Effects of cadmium stress on active oxygen generation, lipid peroxidation and antioxidant enzyme activities in radish seedlings. Journal of Plant Physiology and Molecular Biology, 2004, 30 (4) : 469-474.

[ 7 ] Stobart A K, Griffiths W T, Ameen-Bukhari I, Sherwood R P. The effects of $\mathrm{Cd}^{2+}$ on the biosynthesis of chlorophyll in leaves of barley. Plant Physiology, 1985, 63(3): 293-298.

[ 8 ] Hao Z B, Cang J, Xu Z. Experimental Plant Physiology. Harbin: Harbin Institute of Technology Press, 2004.

[ 9 ] Zhang Z L. Plant Physiology Experimental Guide. Beijing: Higher Education Press, 2003.

[10] Chen S Y. Injury of membrane lipid peroxidation to plant cell. Plant Physiology Communications, 1991, 27(2) : 84-90.

[11] Tan S D, Zhu M Y, Dang H S, Wang Y, Zhang Q F. Physiological responses of Bermudagrass (Cynodon dactylon (L. ) Pers. ) to deep submergence stress in the Three Gorges Reservoir Area. Acta Ecologica Sinica, 2009, 29(2) : 3685-3691.

[12] Ji W D, Shi G X, Yang H Y, Xu Q S, Yu Y, Zhang H. Effects of $\mathrm{Cu}^{2+}$ stress on leaf physiological indice and ultrastructure of Potamogeton malaianus. Chinese Journal of Applied Ecology, 2007, 18(12) : 2727-2732.

[13] Huang Y S, Luo G H, Guan K W. Peroxidation damage of oxygen free radicals induced by cadmium to plant. Acta Botanica Sinica, 1997, 39 (6) : 522-526.

[14] Gu Y F, Ding S Y, Li T T, Wang X, Li J J, Zhang L X. Effects of saline stress on dry matter partitioning and ecophysiological characteristics of winter wheat seedlings. Acta Ecologica Sinica, 2009, 29(2): 840-845.

[15] Lal A, Edwards G E. Analysis of inhibition of photosynthesis under water stress in the C4 species Amaranthus cruentus and Zeamays: electrontransport, $\mathrm{CO}_{2}$ fixation and carboxylation capacity. Australian Journal of Plant Physiology, 1996, 23 (4) : 403-412.

[16] Huang F L, Xia B C, Dai X. Bacteria ecology in planting-culturing system. Chinese Journal of Applied Ecology, 2004, 15(6) : $1030-1034$.

[17] Chen L S, Liu X H. Effect of high temperatures tress on cell membrane permeability and photosynthetic pigment in leaves of peach and pomelo. Journal of Wuhan Botanical Research, 1997,15(3):233-237.

[18 ] Yang M, Mao K, Gou W L, Zhao B. The effect of shade to Chlorophyll contents. Journal of Sichuan Grassland, 2004, (3) : 20-22.

[19] Qiu Y, Li Z D, Yu R Y. Study on the relation berween the stability of Betula platyphylla population and the fire disturbance. Bulletin of Botanical Research, 1998, 18(3): 321-327.

[20] Wang Y T. A Study on the Natural Regeneration of Pinus Densata Forest Burned Areas in Western Sichuan Province [D]. Beijing: Beijing Forestry University, 2005.

[21] Xing W, Ge Z W, Li J Q. The effect of fire severity on the Larix gmelini community in North Great Xing' an Mountains. Science Technology and Engineering, 2006, 6(14) : 2042-2046.

\section{参考文献:}

[ 1 ] 周以良. 中国大兴安岭植被. 北京: 科学出版社, 1991.

[ 2 ] 胡海清. 林火与环境. 哈尔滨: 东北林业大学出版社, 1999.

[ 3 ] 胡海清, 刘慧荣, 耿玉超. 火烧对人工林红松樟子松树木的影响. 东北林业大学学报, 1992, 20(2): 43-48. 
[ 4 ] 周道玮, 姜世成, 胡勇军. 草原植物高生长、体内水分和叶绿素含量对火烧的反应. 东北师大学报: 自然科学版, 1999, (4): 91-95.

[ 6 ] 汤春芳, 刘云国, 曾光明, 李程峰, 徐卫华. 镉胁迫对夢卜幼苗活性氧产生、脂质过氧化和抗氧化酶活性的影响. 植物生理与分子生物 学学报, 2004, 30(4): 469-474.

[ 8 ] 郝再彬, 苍晶, 徐仲. 植物生理实验. 哈尔滨: 哈尔滨工业大学出版社, 2004.

[ 9 ] 张志良. 植物生理学实验指导. 北京: 高等教育出版社, 2003.

[10］陈少裕. 膜脂过氧化对植物细胞的伤害. 植物生理学通讯, 1991, 27(2): 84-90.

（11］谭淑端, 朱明勇, 党海山, 王勇, 张全发. 三峡库区狗牙根对深淹胁迫的生理响应. 生态学报, 2009, 29(7): 3685-3691.

[12] 计汪栋, 施国新, 杨海燕, 徐勤松, 许哗, 张慧. 铜胁迫对竹叶眼子菜叶片生理指标和超微结构的影响. 应用生态学报, 2007, 18(12)： 2727-2732.

[13] 黄玉山, 罗广华, 关棨文. 镉诱导植物的自由基过氧化损伤. 植物学报, 1997, 39(6): 522-526.

[14] 谷艳芳, 丁圣彦, 李婷婷, 王欣, 李俊娇, 张丽霞. 盐胁迫对冬小麦幼苗干物质分配和生理生态特性的影响. 生态学报, 2009, 29(2)： 840-845.

[16] 黄凤莲, 夏北成, 戴欣. 滩涂海水种植-养殖系统细菌生态学研究. 应用生态学报, 2004, 15(6)：1030- 1035.

[17] 陈立松,刘星辉. 高温胁迫对桃和柚细胞膜透性和光合色素的影响. 武汉植物学研究, 1997,15( 3): 233-237.

[18］杨猀，毛凯，荷文龙，赵波. 遮荫胁迫对叶绿素含量的影响. 四川草原，2004，(3): 20-22.

[19] 邱扬, 李湛东, 于汝元. 白桦种群的稳定性与火干扰关系的研究. 木本植物研究, 1998, 18(3) : 321-327.

[20］王玉涛. 川西高山松林火烧迹地天然更新研究 [D]. 北京: 北京林业大学, 2005.

[21] 邢玮, 葛之威, 李俊清. 大兴安岭北部林区林火干扰强度对兴安落叶松群落影响研究. 科学技术与工程, 2006, 6(14): 2042-2046. 


\section{ACTA ECOLOGICA SINICA Vol.32, No.8 April,2012(Semimonthly) CONTENTS}

Physiological responses of five deciduous broad-leaved tree seedlings in the Northeast Area of China to burning

The occurrence regularity of psyllid in Haloxylon spp and its influencing factors

The

The estimating of the spatial distribution of forest biomass in China based on remote sensing and downscaling techniques …….......

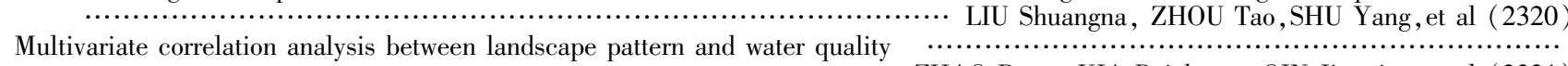

. XHAO Peng, XIA Beicheng, QIN Jianqiao, et al (2331)

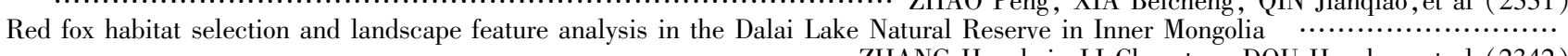

Research on assemblage characteristics of macroinvertebrates in the Yalu Tsangpo River Basin ……..................................

................................................................ XU Mengzhen, WANG Zhaoyin, PAN Baozhu, et al (2351)

Climate change induced potential range shift of the crested ibis based on ensemble models ……... ZHAI Tianqing, LI Xinhai (2361)

Analysis of the sources of second generation meadow moth populations that immigrated into Chinese pastoral areas in 2010

ZHANG Li, ZHANG Yunhui, ZENG Juan, et al (2371)

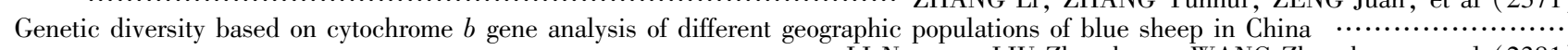

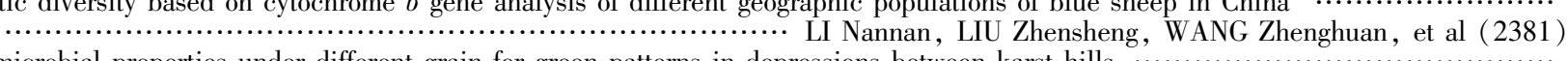

Soil microbial properties under different grain-for-green patterns in depressions between karst hills …................................

Ecosystem and soil respiration of a poplar plantation on a sandy floodplain in Northern China ……....................................

Estimating total nitrogen content in water body based on reflectance from wetland vegetation Z..........................................

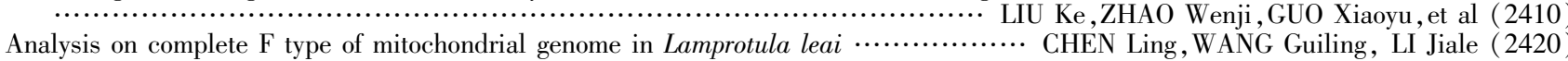

CHEN Ling, WANG Guiling, LI Jiale (2420)

The source-sink landscape pattern change and its effect on phosphorus pollution in Yuqiao watershed

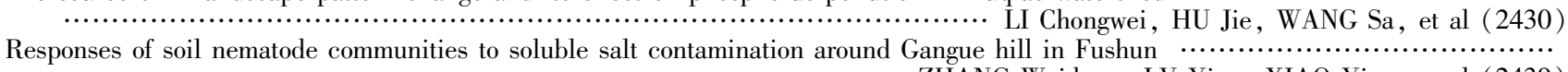

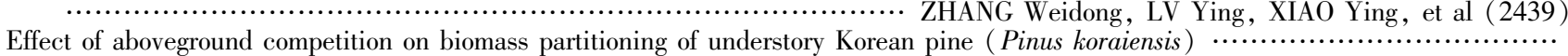
..................................................................... WANG Jinsong, FAN Xiuhua, FAN Juan, et al (2447)

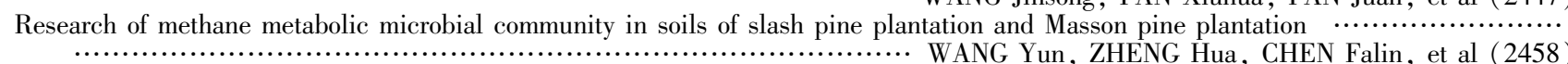

$\delta^{13} \mathrm{C}$ values of stem phloem water soluble sugars of Pinus massoniana and Cunninghamia lanceolata response to meteorological factors ……........................................... LU Yuxi, WANG Zhenxing, ZHENG Huaizhou, et al (2466)

Soil respiration patterns during restoration of vegetation in the Shapotou area, Northern China

GAO Yanhong, LIU Lichao, JIA Rongliang, et al (2474)

Dynamics of caloric value of Robinia pseudoacacia L. energy forest in the west of Henan Province ……..............................

Ex-situ symbiotic seed germination of Dendrobium catenatum ...................... WU Huifeng, SONG Xiqiang, LIU Hongxia (2491)

Effects of red/far red ratio on morphological index, leaf area and dry matter partitioning of cut chrysanthemum flower

YANG Zaiqiang, ZHANG Jibo, LI Yongxiu, et al (2498)

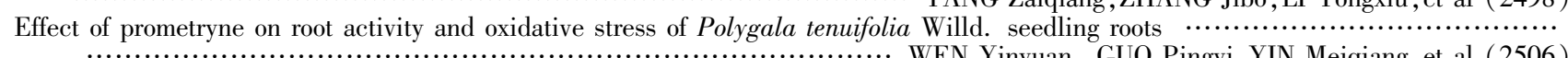

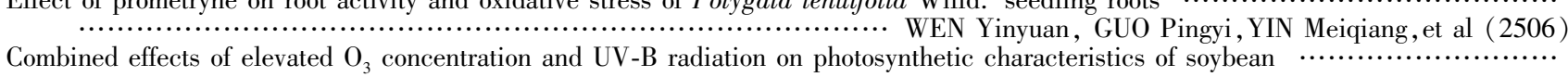

Nutrients transfer for host plant and litter decompositon by AMF in Karst soil

ZHENG Youfei, XU Weimin, WU Rongjun, et al (2515)

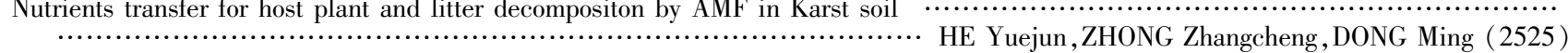

The dynamics of bacteria community diversity during the fermentation process of traditional soybean paste

Effect of site-specific fertilization on soil phosphorus in purple garden soil

GE Jingping, CHAI Yangyang, CHEN Li, et al (2532)

SUN Qianqian, WANG Zhengyin, ZHAO Huan, et al (2539)

A method of determining standards for ecological compensation in agricultural areas, giving priority to environmental flows in water allocation …............................................................................... PANG Aiping, SUN Tao (2550)

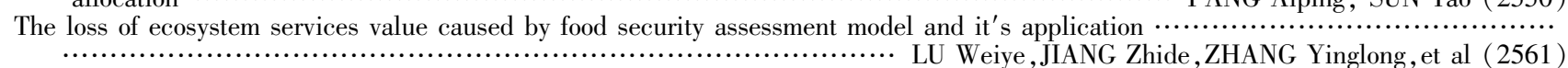

Review and Monograph

Review of the current situation of coastal ecological engineering using dredged marine sediments and prospects for potential application in China

\section{Discussion}

Quorum sensing in anaerobic ammonium oxidation bacteria

Health evaluation of Dongting Lake based on morphological characters

DING Shuang, ZHENG Ping, ZHANG Meng, et al (2581)

Scientific Note

Effects of mix-leaf litter decomposition of different trees in the Loess Plateau

Changes in soil active organic carbon under different management types of bamboo stands , DU Liangzhen, ZHANG Xiaoxi , et al (2596)

MA Shaojie, LI Zhengcai, WANG Bin, et al (2603)

Effects of drought stress on photosynthesis and associated physiological characters of pepper

OU Lijun, CHEN Bo, ZOU Xuexiao (2612)

Effects of silicon application and drought stress on photosynthetic traits and mineral nutrient absorption of rice leaves

CHEN Wei, CAI Kunzheng, CHEN Jining (2620) 


\section{《生态学报》2012 年征订启事}

《生态学报》是中国生态学学会主办的自然科学高级学术期刊,创刊于 1981 年。主要报道生态学研究原 始创新性科研成果, 特别欢迎能反映现代生态学发展方向的优秀综述性文章; 研究简报; 生态学新理论、新方 法、新技术介绍; 新书评介和学术、科研动态及开放实验室介绍等。

《生态学报》为半月刊,大 16 开本, 280 页,国内定价 70 元/册, 全年定价 1680 元。

国内邮发代号:82-7 国外邮发代号:M670 标准刊号:ISSN 1000-0933 CN 11-2031/Q

全国各地邮局均可订阅，也可直接与编辑部联系购买。欢迎广大科技工作者、科研单位、高等院校、图书 馆等订阅。

通讯地址: 100085 北京海淀区双清路 18 号 电 话: (010)62941099; 62843362

E-mail: shengtaixuebao@ rcees. ac.cn址: www. ecologica.cn

编辑部主任 孔红梅 执行编辑 刘天星 段 靖

生 态 学 报

(SHENGTAI XUEBAO)

(半月刊 1981 年 3 月创刊)

第 32 卷 第 8 期 (2012 年 4 月)

\section{ACTA ECOLOGICA SINICA}

( Semimonthly, Started in 1981)

Vol. 32 No. 82012

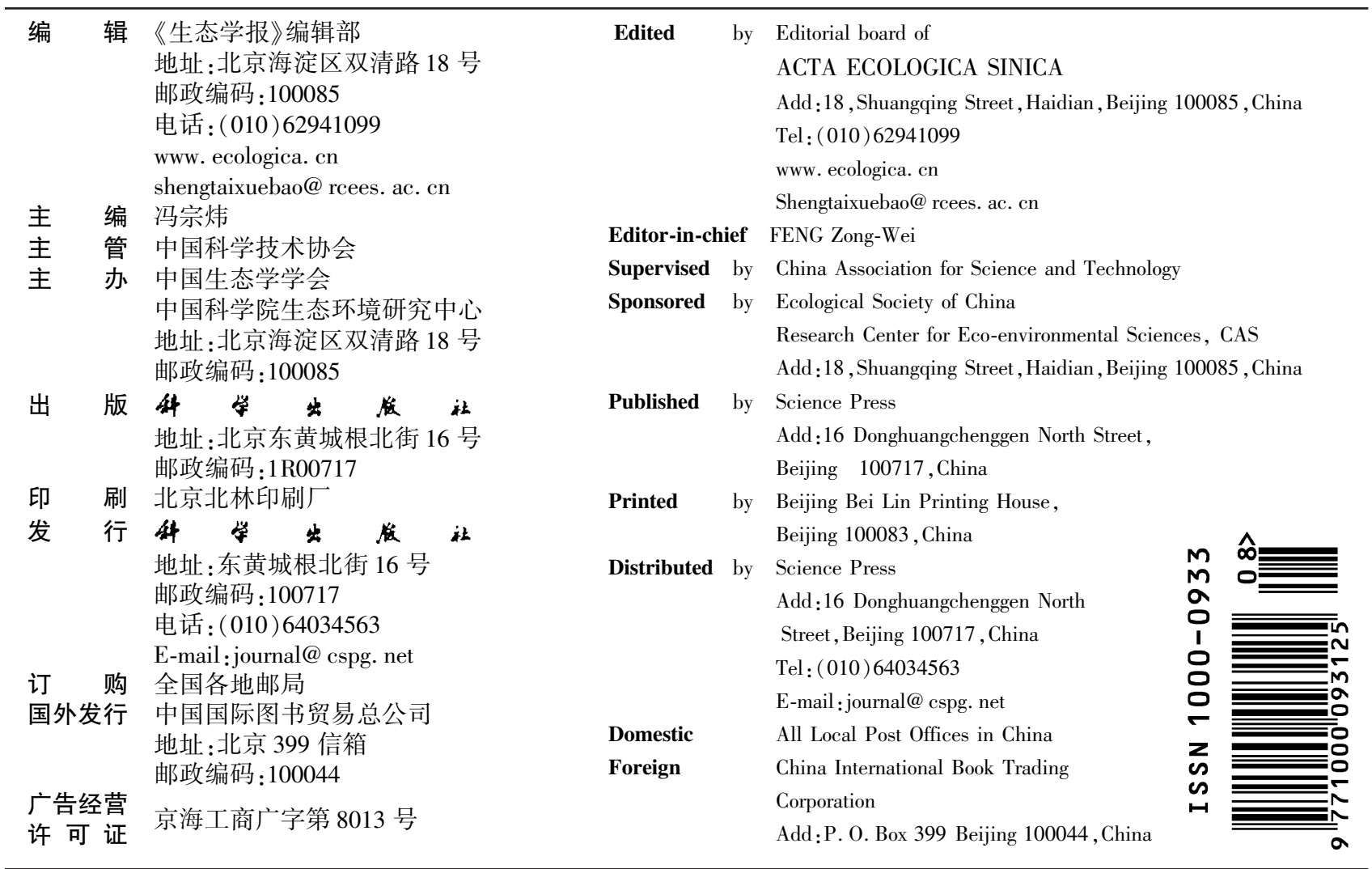

ISSN 1000-0933

CN $11-2031 / \mathrm{Q}$

国内外公开发行

国内邮发代号 82-7

国外发行代号 M670

定价 70.00 元 